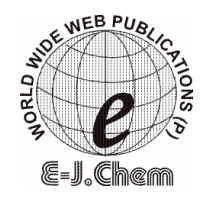

http://www.e-journals.net
ISSN: 0973-4945; CODEN ECJHAO

E-Journal of Chemistry

2009, 6(3), 871-879

\title{
Nucleation Kinetics, Growth and Characterization Studies of a Diamagnetic Crystal-Zinc Sulphate Heptahydrate (ZSHH)
}

\author{
R. KANAGADURAI ${ }^{\#}$, R. DURAIRAJAN ${ }^{\natural *}$, R. SANKAR ${ }^{\S}$, \\ G. SIVANESAN, S. P. ELANGOVAN" and R. JAYAVEL ${ }^{\S}$
}

\author{
"Department of Physics, R.S. Govt. College, Thanjavur-613 005, India. \\ IDepartment of Chemistry, R.S.Govt. College, Thanjavur-613 005, India. \\ ${ }^{\S}$ Crystal Growth Centre, Anna University, Chennai-600 025, India. \\ J.J.College of Arts and Science, Pudukkottai-622 404, Tamil Nadu, India. \\ chem_durai@yahoo.com
}

Received 31 October 2008; Revised 13 January 2009; Accepted 16 January 2009

\begin{abstract}
Solubility, metastable zone width and induction period measurements have been performed on zinc sulphate heptahydrate ( $\mathrm{ZSHH})$. Interfacial tension values determined from induction period measurements have been used for the evaluation of the nucleation parameters such as radius of critical nucleus and the free energy of formation of critical nucleus. ZSHH crystallizes in the orthorhombic structure. Crystals of diamagnetic zinc sulphate heptahydrate have been grown by temperature lowering solution growth technique with the optimized growth parameters. The as-grown ZSHH crystals were characterized by the powder X-ray diffraction, UV-VIS absorption and transmittance, FT-IR absorption, TG-DTA, microhardness and etching studies.
\end{abstract}

Keywords: ZSHH, Nucleation studies, Induction period, Solubility, Diamagnetic.

\section{Introduction}

Diamagnetic Zinc sulphate heptahydrate finds wide applications in solar systems for solar energy storage, in making lithophone, in coagulation baths for rayon, in electrolyte for zinc plating, in medicine as an astringent and emetic and used to supply zinc in animal feeds, fertilizers, agricultural sprays, as a moderant in dyeing, as a preservative for skins and leather. But quite often inadequate transparency, poor optical quality and inability to grow large size crystals have impeded the use of single crystals of diamagnetic materials in practical device application. Growth of bulk single crystals of these materials has been a subject of perennial concern in order to use them for device application. 
Single crystals of ZSHH were grown in very small size by silica gel method ${ }^{1}$. In order to optimize the growth parameters for growing bulk crystals, a systematic investigation has been made on the experimental determination of solubility, metastable zone width and induction period values. The interfacial energy has been estimated using the experimentally determined induction period values. Using the optimized growth parameters bulk crystals of size $70 \times 11 \times 4 \mathrm{~mm}^{3}$ have been grown. Optical, thermal properties, mechanical strength and surface analysis of ZSHH crystal have also been studied.

\section{Experimental}

The calculated amounts of the ZSHH salts were dissolved in deionized water. This solution was heated and kept for slow evaporation to dryness at room temperature. The purity of the salt was improved by successive recrystallisation process. The solubility of ZSHH was determined for four different temperatures, $30,35,40$, and $45^{\circ} \mathrm{C}$. by dissolving the solute in deionized water in an air tight container maintained at a constant temperature with stirring. After attaining saturation, the equilibrium concentration of the solute was analyzed gravimetrically. The same procedure was repeated and the solubility curves for different temperatures were drawn. Figure (1) shows the solubility curve for zinc sulphate heptahydrate at different temperatures.

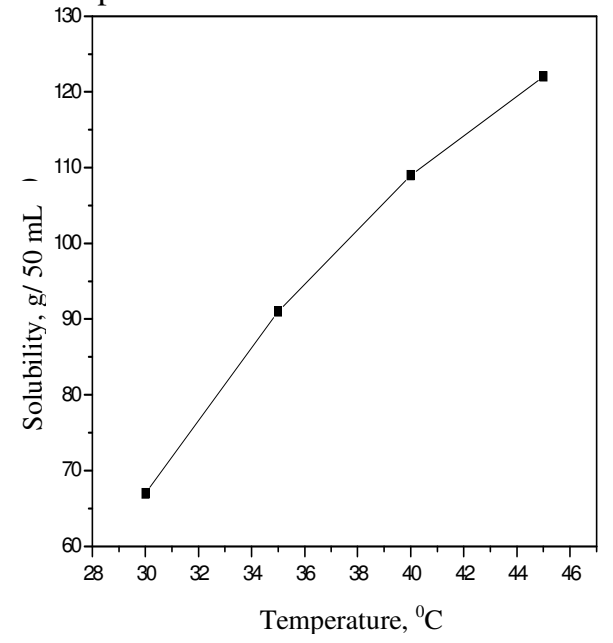

Figure 1. Solubility of ZSHH as a function temperature in aqueous solution.

\section{Metastable zone width and induction period measurements}

Saturated solution of zinc sulphate heptahydrate was prepared from solubility experiment. The metastable zone width was measured by the conventional polythermal method ${ }^{2,3}$. The studies were carried out in a constant temperature bath controlled to an accuracy of $\pm 0.05{ }^{\circ} \mathrm{C}$, provided with a cryostat for cooling below room temperature. A constant volume of $150 \mathrm{~mL}$ of the solution was used for all the experiments. The solution was heated to $5{ }^{\circ} \mathrm{C}$ above the supersaturation temperature for homogenization and was kept at the superheated temperature for one hour before cooling. It was continuously stirred using a motorized stirrer to ensure homogeneous concentration and temperature throughout the entire volume of the solution. The temperature of the bath was reduced at a rate of $0.5{ }^{\circ} \mathrm{C}$ per minute with continuous stirring after the stabilization. The temperature at which the first speck of a particle appeared was noted. The first speck of crystal obtained is taken as critical nucleus. The time taken for 
the formation of the critical nucleus is called induction period $(\tau)$ and the induction period of zinc sulphate heptahydrate was measured by means of isothermal method. Repeated trials were carried out to ensure reproducibility. It was observed that metastable zone width decrease with increase of temperature as shown in the Figure 2.

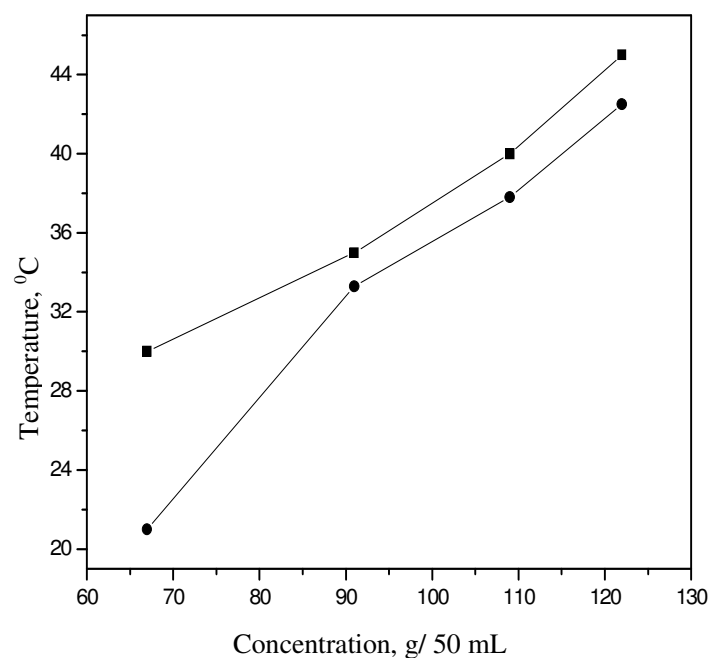

Figure 2. Meta stable zone width as a function of temperature in aqueous solution.

\section{Interfacial tension}

Interfacial tension of the crystal and solution interface is an important parameter involved in the theory of nucleation and growth kinetics. In the present investigation, in order to estimate the critical nucleation parameters, the interfacial tension has been calculated on the basis of the classical theory of homogeneous nucleation ${ }^{4-6}$.

The interfacial tension of the solid relative to this solution has been calculated from the relation

$$
\sigma^{3}=\frac{3 \ln \tau R^{3} T^{3}(\ln S)^{2}}{16 \pi V^{2} N}
$$

Where $\sigma$ is the interfacial tension, $\mathrm{V}$ is the molar volume of the crystal, $\mathrm{N}$ is the Avogadro's number, $R$ is the gas constant and $S$ is the relative supersaturation $\left(\mathrm{S}=\mathrm{C} / \mathrm{C}^{*}\right)$ where $\mathrm{C}$ is the actual concentration and $\mathrm{C}^{*}$ is the equilibrium concentration. Figure (3) shows the variation of induction period as a function of supersaturation ratio for various temperatures. According to the classical homogeneous nucleation theory the free energy required to form a spherical nucleus is given by

$$
\Delta G=\frac{4}{3} \pi r^{3} \Delta G_{v}+4 \pi r^{2} \sigma
$$

Where $\Delta \mathrm{Gv}$ is the energy change per unit volume, $\mathrm{r}$ is the radius of the nucleus. At the critical state, the free energy of formation obeys the condition that $\mathrm{d}(\Delta \mathrm{G} / \mathrm{dr})=0$. Hence the radius of the critical nucleus is expressed as $r^{*}=\frac{-2 \sigma}{\Delta G_{v}}$, where $\Delta G_{v}=-k T \ln S / v$, where $\mathrm{V}$ is the molar volume, $\mathrm{S}$ is the relative super saturation.

Hence, $\quad r^{*}=-\frac{2 v \sigma}{k T \ln S}$ 
The critical free energy is given by

$$
\Delta G^{*}=\frac{16 \pi \sigma^{3} v^{2}}{3 \Delta G_{v}{ }^{2}}
$$

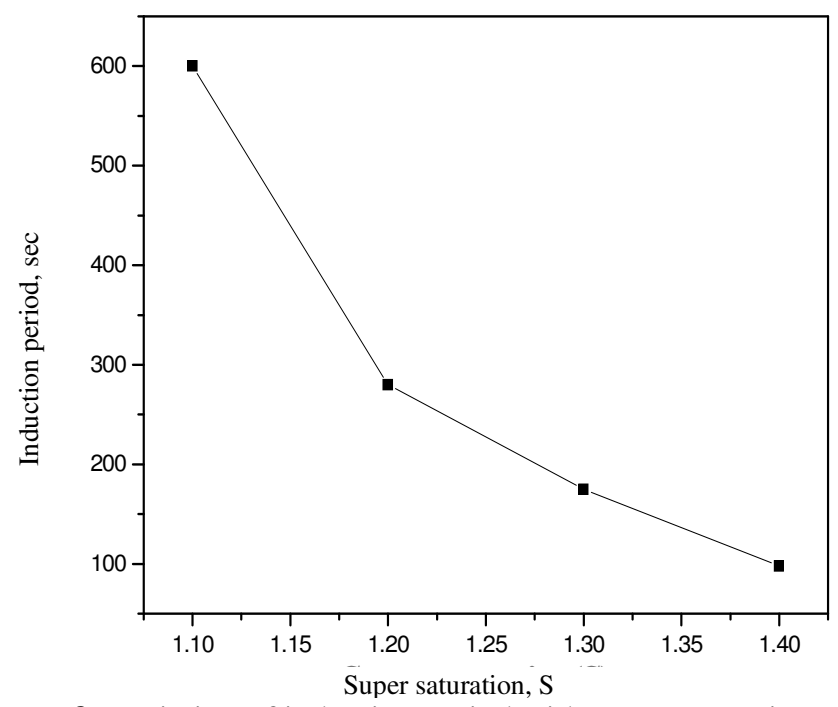

Figure 3. Variation of induction period with super saturation ratio for ZSHH solution.

ZSHH possesses the interfacial energy ranging from 1.7049 to $3.5368 \mathrm{~mJ} / \mathrm{m}^{2}$. The energy of formation $\left(\Delta \mathrm{G}^{*}\right)$ and radius $\left(\mathrm{r}^{*}\right)$ of the critical nucleus of $\mathrm{ZSHH}$ were found to be from 2.8125 to $2.0149 \mathrm{~kJ} / \mathrm{mol}$ and from $1.985 \mathrm{~nm}$ to 1.1665 respectively at different supersaturation level. Experimentally determined values of induction period, interfacial tension, critical nucleus and critical free energy of formation of ZSHH crystal are shown in Table 1. The interfacial tension increases with supersaturation as shown in Figure 4.

Table 1. Experimentally determined values of induction period, interfacial tension, critical nucleus and critical free energy of formation of zinc sulphate hepta hydrate crystal.

\begin{tabular}{ccccc}
\hline $\begin{array}{c}\text { Supersaturation } \\
\mathrm{S}\end{array}$ & $\begin{array}{c}\text { Induction } \\
\text { period, } \mathrm{sec}\end{array}$ & $\begin{array}{c}\text { Interfacial } \\
\text { tension } \sigma, \mathrm{mJ} / \mathrm{m}^{2}\end{array}$ & $\begin{array}{c}\text { Critical } \\
\text { nucleus }{ }^{*}, \mathrm{~nm}\end{array}$ & $\begin{array}{c}\text { Critical free energy of } \\
\text { formation } \Delta \mathrm{G}^{*} \mathrm{~kJ} / \mathrm{mol}\end{array}$ \\
\hline 1.1 & 600 & 1.7049 & 1.985 & 2.8125 \\
1.2 & 280 & 2.5182 & 1.5327 & 2.4769 \\
1.3 & 175 & 3.1176 & 1.3186 & 2.2697 \\
1.4 & 98 & 3.5368 & 1.1665 & 2.0149 \\
\hline
\end{tabular}

\section{Bulk crystal growth}

To grow bulk crystal, the supersaturated solution of zinc sulphate heptahydrate was kept in a constant temperature bath with an accuracy of $\pm 0.01^{\circ} \mathrm{C}$ at $45^{\circ} \mathrm{C}$. The seed crystal of $\mathrm{ZSHH}$, obtained by slow evaporation method, was suspended in the supersaturated solution. The temperature of the bath was reduced at the rate of $0.05^{\circ} \mathrm{C}$ per day. Good transparent singlecrystal of ZSHH was obtained over a growth period of 20 to 25 days. Crystal of maximum dimensions $70 \times 11 \times 4 \mathrm{~mm}^{3}$ grown from aqueous solution by temperaturelowering method is shown in the Figures 5(a) and 5(b) 


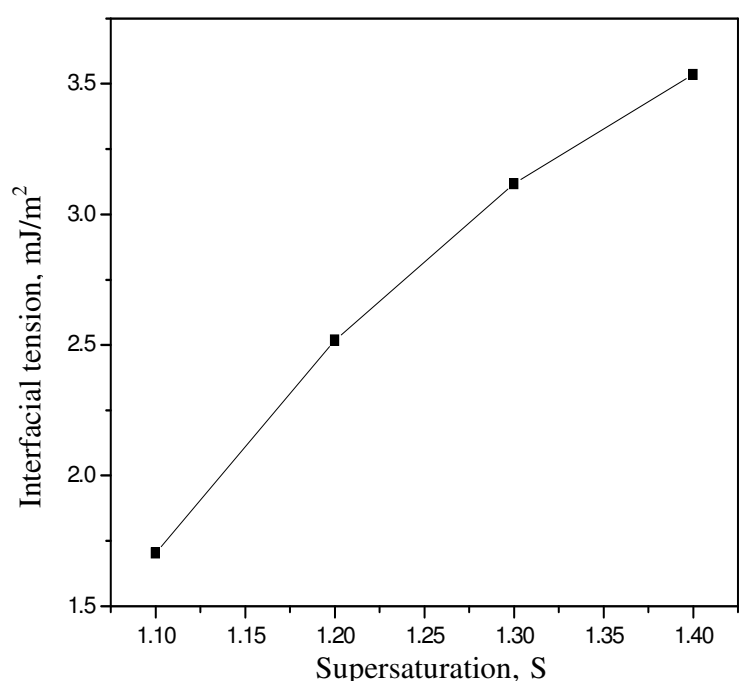

Figure 4. Linear relationships between interfacial tension and supersaturation.

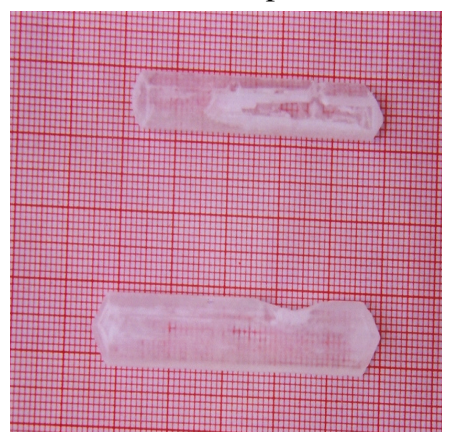

(a)

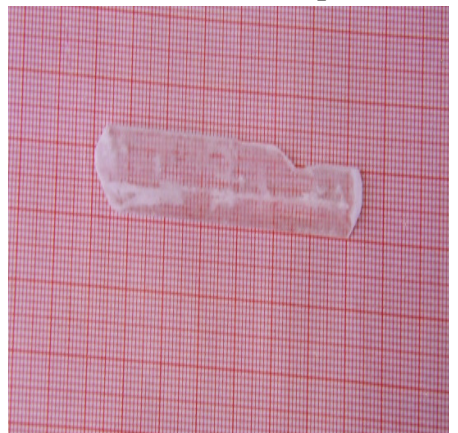

(b)

Figure 5. (a)\&(b) As- grown crystals of ZSHH grown by solvent evaporation method.

\section{Characterization studies}

Powder X-ray diffraction analysis was carried out using a Rich Seifert diffractometer with $\mathrm{CuK}_{\alpha}(\lambda=1.5418 \AA)$ radiation to verify the correctness of lattice parameter values. The FTIR spectra of ZSHH crystals were recorded in the range $400-4000 \mathrm{~cm}^{-1}$ employing a PerkinElmer spectrometer by $\mathrm{KBr}$ pellet method in order to study the presence of the functional groups of the as-grown zinc sulphate heptahydrate single crystal. Linear optical properties of the crystals were studied using a Shimadzu UV-Visible spectrophotometer. Thermal analysis (TG and DTA) was performed on the grown crystals to study the thermal stability of the sample. Etching studies were made on the grown ZSHH single crystals.

\section{Results and Discussion}

As-grown zinc sulphate heptahydrate single crystals are identified by taking powder X-ray diffraction patterns. The indexed pattern of $\mathrm{ZSHH}$ is used to calculate lattice parameters. The values are found to be in good agreement with that of the reported values ${ }^{7,8}$.

FT-IR spectrum of zinc sulphate heptahydrate crystal was recorded. The absorption due to various functional groups is shown in Figure 6. The stretching vibrations of the water molecule 
are expected in the region $3000-3600 \mathrm{~cm}^{-1}$. The broad vibrational band observed at $3301.6 \mathrm{~cm}^{-1}$ is attributed to the symmetric stretching mode of the water molecule. The medium broad band noticed at $1620.2 \mathrm{~cm}^{-1}$ is assigned to the bending vibrational mode of water molecules. The band observed at $754.6 \mathrm{~cm}^{-1}$ is assigned to the liberational mode of water molecules. In general, a free $\mathrm{SO}_{4}{ }^{2-}$ ion has $\mathrm{T}_{\mathrm{d}}$ symmetry and has four fundamental vibrations namely a non degenerate mode $\left(v_{1}\right)$ at $981 \mathrm{~cm}^{-1}$, a doubly degenerate mode $\left(v_{2}\right)$ and triply degenerate vibrations $\left(v_{3}\right.$ and $\left.v_{4}\right)$ at $1104 \mathrm{~cm}^{-1}$ and $613 \mathrm{~cm}^{-1}$ respectively ${ }^{9}$. The peak observed at 1102.4 $\mathrm{cm}^{-1}$ is attributed to the triply degenerate symmetric stretching mode, $\left(v_{3}\right) \mathrm{SO}_{4}{ }^{2-}$. The band observed at $459.2 \mathrm{~cm}^{-1}$ is assigned to the doubly degenerate $\left(v_{2}\right) \mathrm{SO}_{4}{ }^{2-}$ mode. The peak appeared at $982.9 \mathrm{~cm}^{-1}$ is reasonably assignable to the $\left(v_{1}\right) \mathrm{SO}_{4}{ }^{2-}$ non degenerate mode. The mode at $625.5 \mathrm{~cm}^{-1}$ is assigned as the triply degenerate vibrations $\left(v_{4}\right) \mathrm{SO}_{4}{ }^{2-}$. The above assignment agrees with that reported by Sivanesan $e t a l^{10}$ for triglygine sulphate (TGS).

The grown zinc sulphate heptahydrate crystal was crushed into fine powder and TGA and DTA spectra were recorded (Figure 7) in the temperature range from room temperature to $700{ }^{\circ} \mathrm{C}$ at a heating rate of $10{ }^{\circ} \mathrm{C}$ per minute. The analysis was performed in air atmosphere.

The compound is thermally stable up to $46.91{ }^{\circ} \mathrm{C}$. The first weight loss occurs at $79.13{ }^{\circ} \mathrm{C}$ due to the loss of three water molecules with a sharp endothermic peak at $73.84{ }^{\circ} \mathrm{C}$ in the DTA spectrum. The sample suffers a second weight loss at $164.46^{\circ} \mathrm{C}$ due to the loss of one more water molecule. Further weight loss takes place at $175.79^{\circ} \mathrm{C}$ with the loss of another two water molecules. The loss of weight at $199.83{ }^{\circ} \mathrm{C}$ in the TG is due to the loss of $\mathrm{SO}_{3}$ molecule and half of a water molecule leaving $\mathrm{ZnO} .1 / 2\left(\mathrm{H}_{2} \mathrm{O}\right)$. Small endothermic changes noticed at $170{ }^{\circ} \mathrm{C}$ and $190.83{ }^{\circ} \mathrm{C}$ are due to dehydration of the sample. The change at $188.01{ }^{\circ} \mathrm{C}$ appears to be exothermic.

In a crystalline material the region of transparency to electromagnetic radiation defines the intrinsic loss mechanisms and also theoretical transmittance achievable within this region. The UV-Visible spectrum of zinc sulphate heptahydrate was scanned between 200 and $1100 \mathrm{~nm}$ is shown in Figure 8. The spectrum has no absorption band between 340 and $1100 \mathrm{~nm}$, hence the zinc sulphate hepta hydrate crystal is expected to be transparent to all the UV-Visible radiations in between these two wavelengths. The UV cut off wavelength of ZSHH is $286 \mathrm{~nm}$.

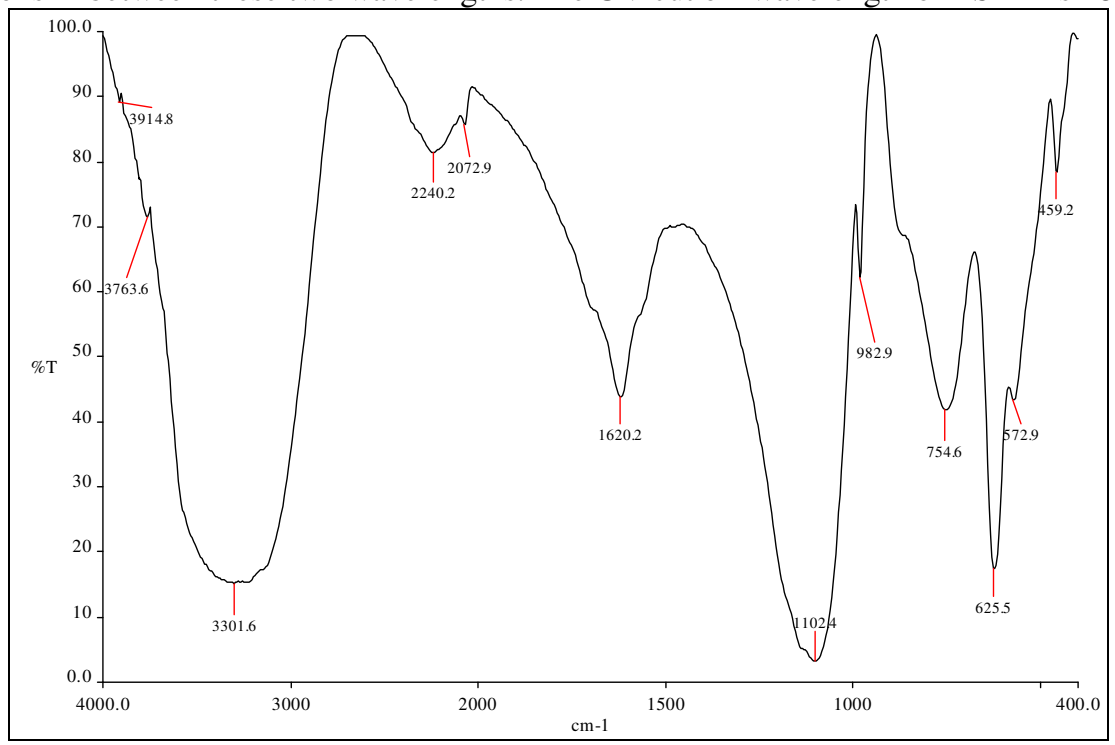

Figure 6. FTIR spectrum of ZSHH crystal. 
In the present work, mechanical property of the grown crystal has been studied with the smooth surfaces of the zinc sulphate hepta hydrate crystals subjected to static indentation test at room temperature using a Leitz-Wetzler hardness tester fitted with diamond pyramidal indenter attached to an incident light microscope.

The micro hardness value was found to decrease with increasing load as shown in Figure 9. The decrease of hardness is due to increase in the strain due to the application of load on the crystal. The work hardening coefficient (n) was determined using the least squares fit method and found to be 0.9. Since $\mathrm{n}$ is less than 2 , the hardness decreases obeying the work hardening coefficient rule ${ }^{11}$. The trend of the hardness $(\mathrm{Hv})$ decreases with load and saturates at higher loads is due to the effect of surface layer ${ }^{12}$ which shows marked effect at the lower loads and after reaching actual lattice at the higher loads, the hardness saturates. Table 2 gives the hardness for different loads and the corresponding fracture toughness $\left(\mathrm{K}_{\mathrm{c}}\right)$ and the brittleness index $(\mathrm{BI})$.

Pyramidal etch hillocks patterns were observed when the ZSHH crystals were subjected to etching studies with different etchants namely, acetic acid $(1 \mathrm{M})$, citric acid $(1.5 \mathrm{M})$, nitric acid $(1 \mathrm{M})$, tartaric acid $(1.5 \mathrm{M})$ and water for different etching periods. Similar hillocks observed in all the cases on the crystal surfaces are non-crystallographic related to the crystal structure which may be due to some sort of over growth in the etching media. The growth hillocks are shown in Figure 10. The hopper like structure observed in the etch pits is indicative of $2 \mathrm{D}$ nucleation mechanism. It is observed that, when selective etchant have been used, the growth mechanism has been found to be only layer growth.

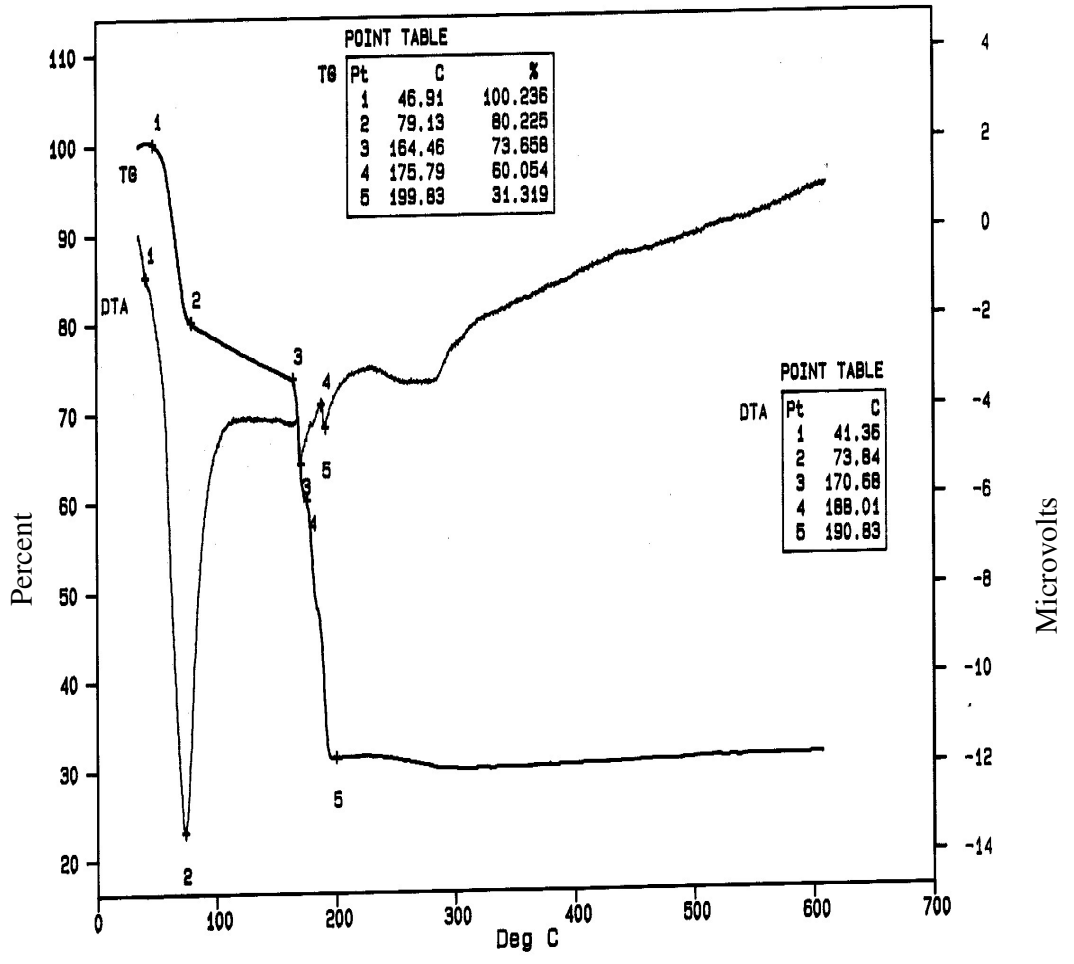

Figure 7. TG - DTA spectra of ZSHH crystal. 


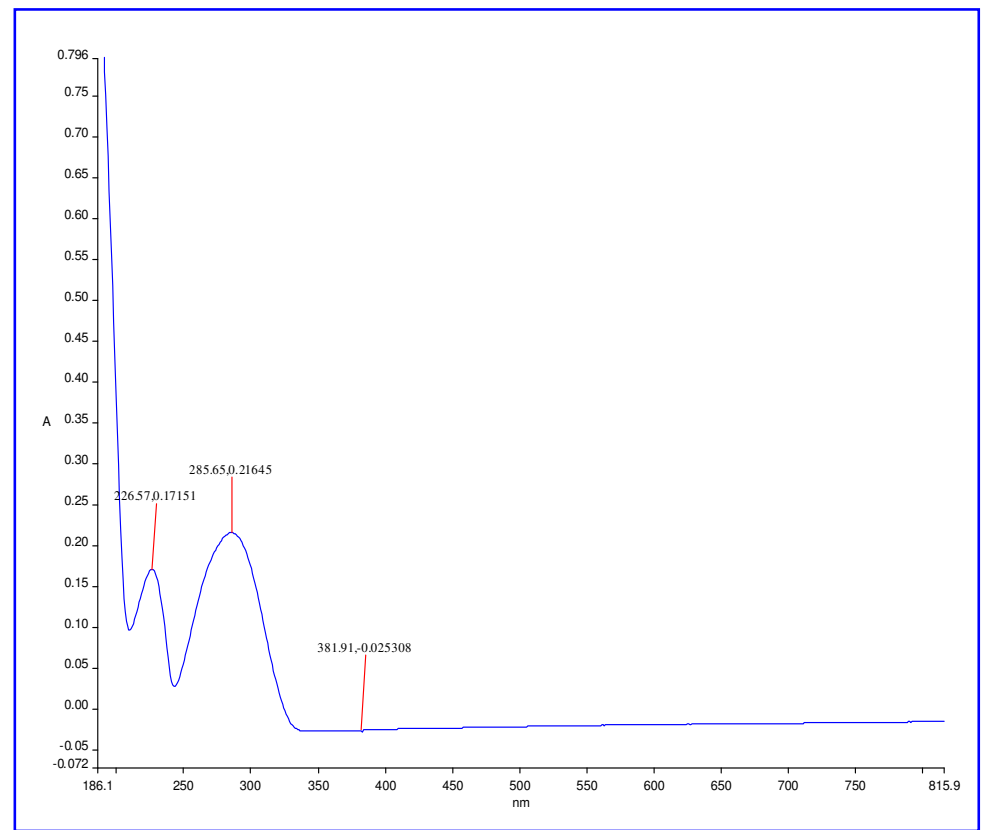

Figure 8. UV-Visible absorption spectrum of zinc sulphate hepta hydrate crystal.

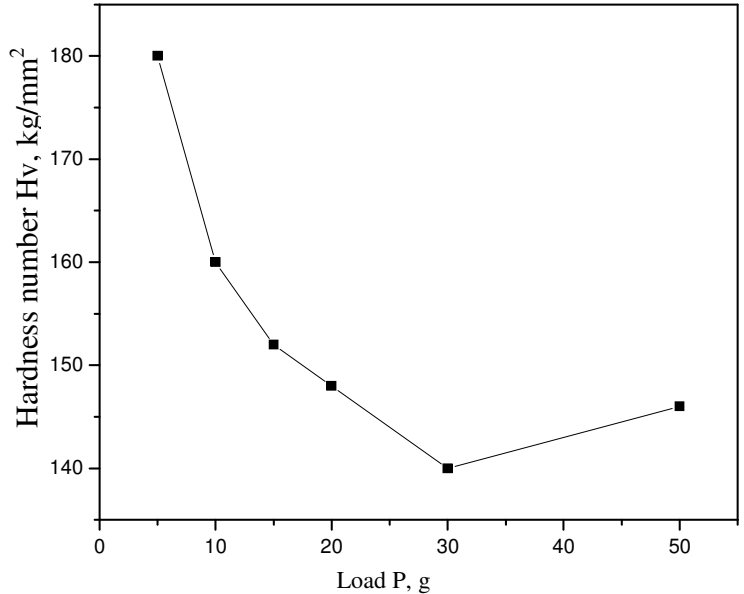

Figure 9. Hardness Number (Hv) vs. Load (P) of ZSHH crystal.

Table 2. Mechanical properties of ZSHH single crystal.

\begin{tabular}{cccc}
\hline Load (P) $10^{-3} \mathrm{~kg}$ & $\mathrm{Hv}, \mathrm{Pa}$ & $\begin{array}{c}\text { Fracture toughness } \\
\mathrm{Kc}, \mu \mathrm{Pa} \mathrm{m}^{1 / 2}\end{array}$ & $\begin{array}{c}\text { Brittleness index } \\
\mathrm{BI}, \mu \mathrm{m}^{-1 / 2}\end{array}$ \\
\hline 5 & 0.180 & 0.1046 & 1.721 \\
10 & 0.160 & 0.1171 & 1.366 \\
15 & 0.152 & 0.1209 & 1.257 \\
20 & 0.148 & 0.1287 & 1.150 \\
30 & 0.140 & 0.1355 & 1.033 \\
50 & 0.146 & 0.1578 & 0.925 \\
\hline
\end{tabular}




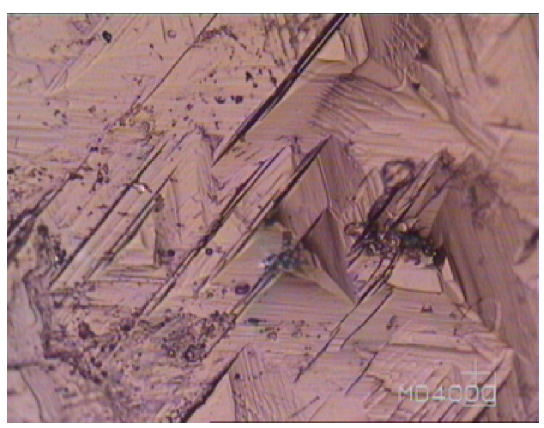

Figure 10. Etching study of Zinc sulphate hepta hydrate (ZSHH) crystal.

\section{Conclusion}

Nucleation kinetics of zinc sulphate heptahydrate has been studied. Growth parameters such as the solubility, metastable zone width, induction period have been determined experimentally. The investigation on the fundamental growth parameter for the aqueous solution growth of ZSHH shows that experimentally determined interfacial tension using the induction period values varies from 1.7049 to $3.5368 \mathrm{~mJ} / \mathrm{m}^{2}$ at the saturation temperature of $45^{\circ} \mathrm{C}$. Interfacial tension plays the vital role in nucleation mechanism. Bulk ZSHH crystals have been grown with the optimized growth parameters. The powder X-Ray diffraction study confirms the lattice parameter value. The presence of functional groups in zinc sulphate heptahydrate has been confirmed by FT-IR spectral analysis. The substance is thermally stable up to of $46.91{ }^{\circ} \mathrm{C}$. The Vickers's microhardness studies reveal that the work hardening coefficient of ZSHH crystal to be 0.9. The hardness for different loads and the corresponding fracture toughness $\left(\mathrm{K}_{\mathrm{c}}\right)$ and the brittleness index (BI) indicate that the crystals are soft and are easily fractured even at lower loads. Pyramidal etch hillocks were observed in the grown ZSHH crystals.

\section{Acknowledgement}

The authors wish to thank Prof. V.Sethuraman, Department of Chemistry, Rajah Serfoji Government College (Autonomous), Thanjavur, for his comments, constructive suggestion and discussion during the preparation of this article.

\section{References}

1. Kanagadurai R, Ph.D Thesis, Bharathidasan University, Trichy, 2007.

2. Nyvlt I, Rychly R and Wutzelova J G, J Cryst Growth., 1970, 6, 151.

3. Zaitseva N P, RashKovich L N and Bagatyarek S V, J Cryst Growth., 1995, 148, 271.

4. Nielson A E and Aig S, J Cryst Growth., 1971, 8, 1.

5. Volmer M and Weber A, J Phys Chem., 1926, 119, 277.

6. Ushasree P M, Muralidharan R, Jayavel R and Ramasamy P, J Cryst Growth, 2000, 210, 741.

7. Anderson J L, Peterson R C and Swainson I P, Miner Mag., 2005, 69(3), 259

8. Baur W H, Acta Crystallogr., 1964, 17, 1361

9. Herzberg G, IR and Raman Spectra of Poly Atomic Molecules, Van Nostrand, New York, $2^{\text {nd }}$ Ed., 1960.

10. Sivanesan G, Kolandaivel P and Selvasekarapandian S, Mat Chem Phys., 1993, 34, 73.

11. West Brook J H and Conrad H, The Science of hardness testing and its Research applications, American Society for metals, Metals Park, Ohio, 1971.

12. Bergina G, Berman I B and Savintsev P A, Sov Phys Crystallogr., 1965, 9, 483. 


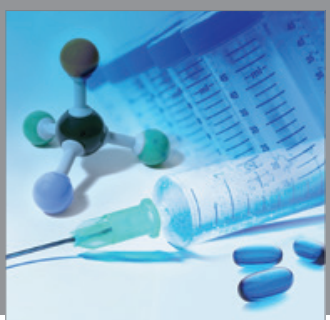

International Journal of

Medicinal Chemistry

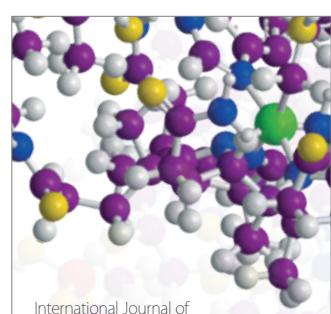

Carbohydrate Chemistry

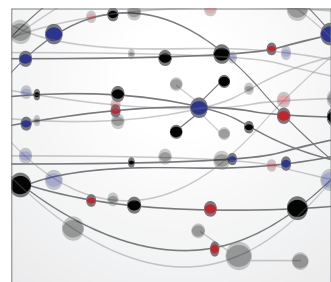

The Scientific World Journal
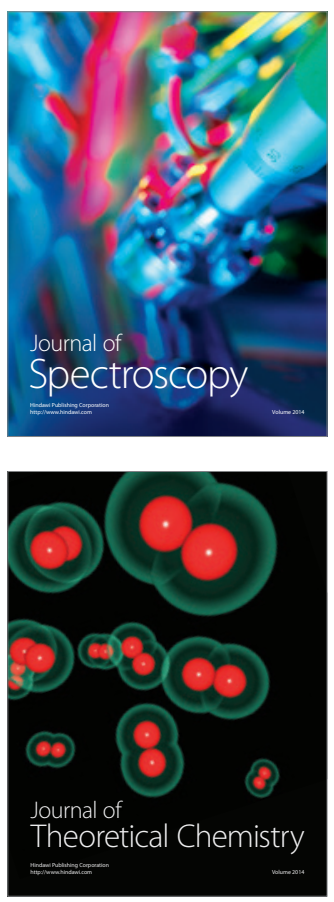
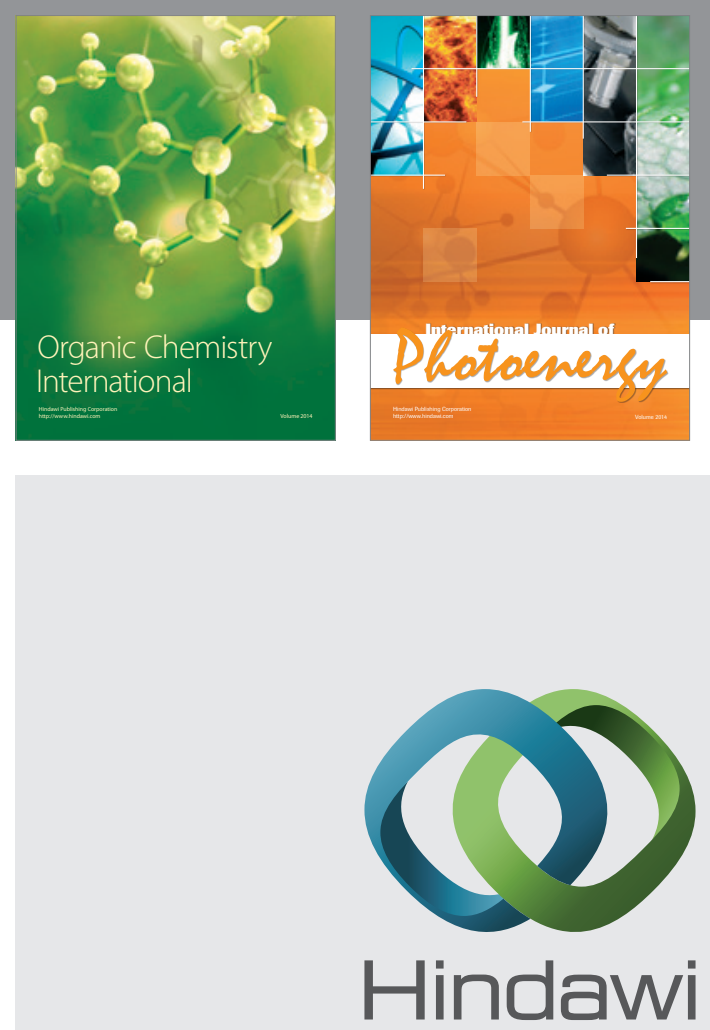

Submit your manuscripts at

http://www.hindawi.com
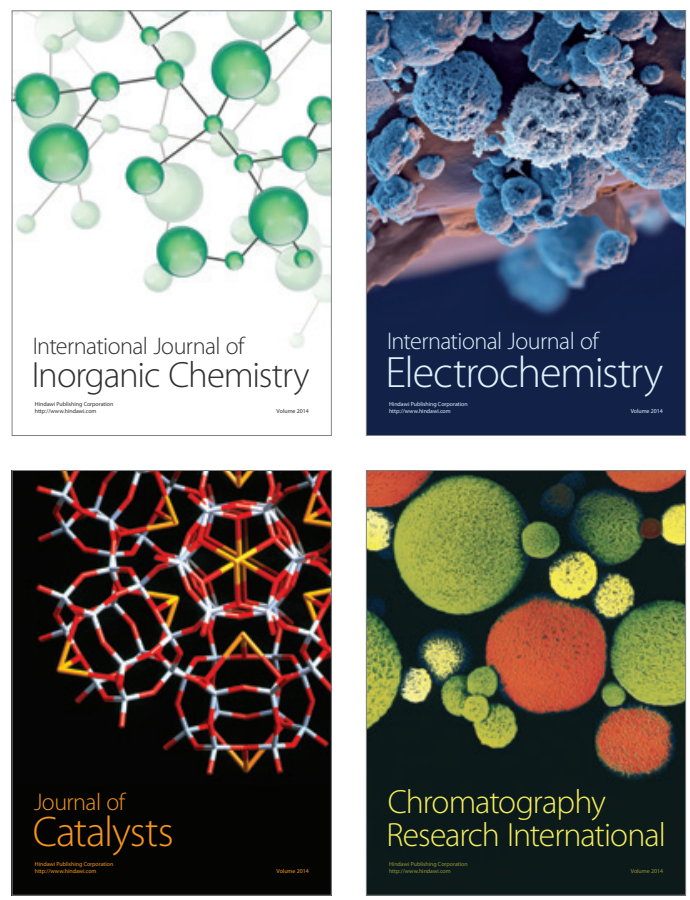
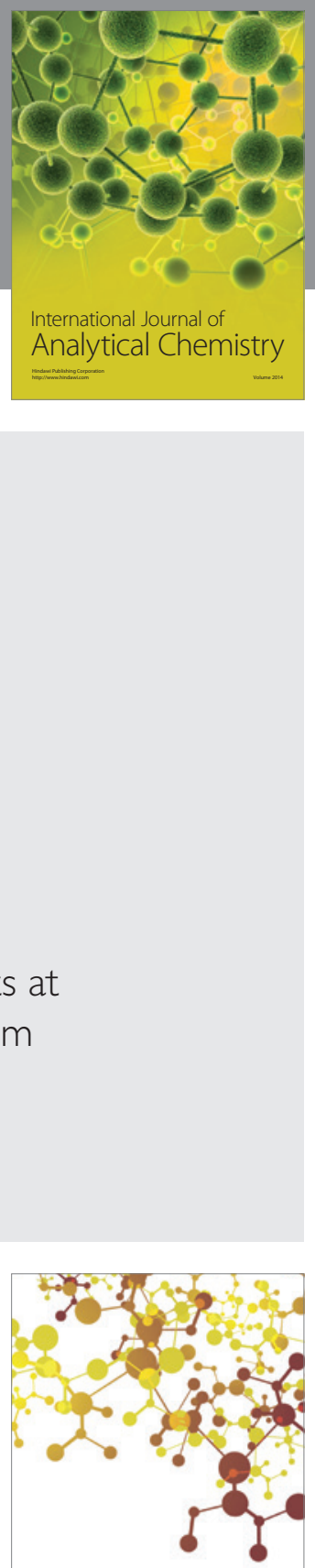

Journal of

Applied Chemistry
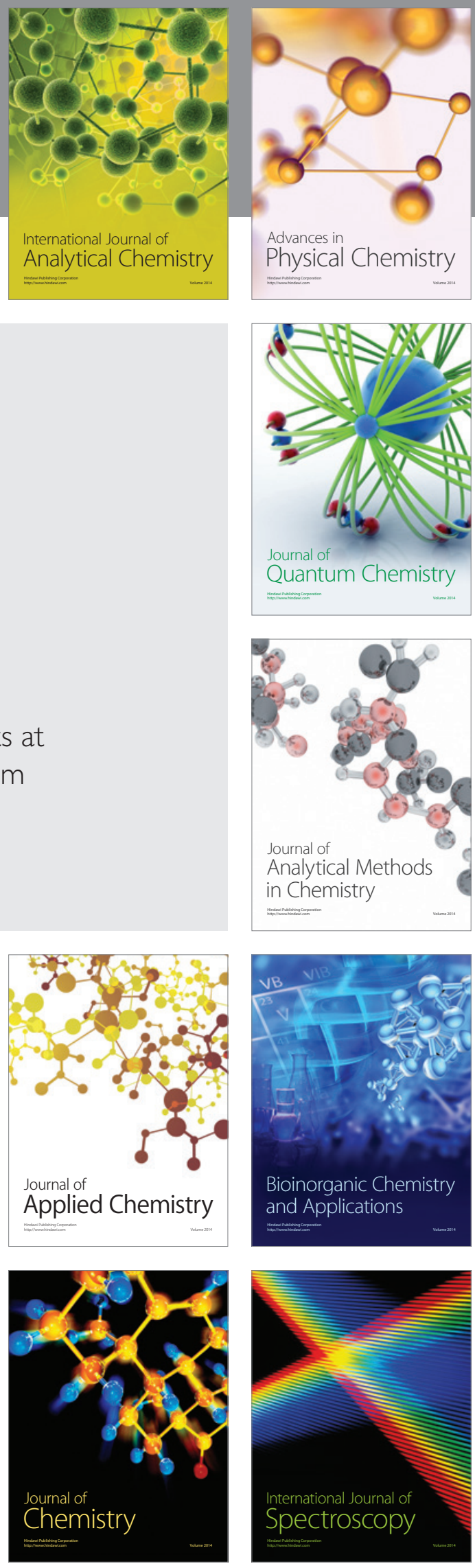